\title{
Corneal Collagen Crosslinking in post-LASIK keratectasia
}

Salgado JP., Khoramnia R., Lohmann CP, Winkler v Mohrenfels C.

Augenklinik Klinikum rechts der Isar,

Technische Universität München, Germany

Keywords: Crosslinking, Keratectasia, LASIK, Cornea

\section{Correspondence:}

Josefina P. Salgado, MD

Augenklinik, Technische Universität München

Ismaningerstr 22

81675 Munich

Germany

Tel: $\quad+498941402320$

Fax: +498941404858

E-Mail:

Financial interest: none of the authors has any financial interest in the technique or devices mentioned in this paper. Informed consent has been signed. 
Abstract:

Background/Aims: To evaluate the effect of corneal collagen crosslinking with riboflavin and UV-A as a treatment option for post-laser in situ keratomileusis (LASIK) keratectasia.

Methods: Crosslinking was carried out in 22 eyes of 15 patients with iatrogenic keratectasia. Follow-up, according to a standardized protocol (UCVA, BCVA, slitlamp examination, pachymetry and topography), was performed preoperatively, 1, 3, 6 and 12 months after crosslinking.

Results: The mean BCVA was 0.19 (SD \pm 0.21 ) logMAR preoperatively, 0.25 (SD \pm 0.17 ) 1 month, 0.20 (SD \pm 0.20 ) 3 months, 0.18 (SD \pm 0.21$) 6$ months and 0.15 (SD 士0.14) 12 months postoperatively (statistically significant postop1-postop6, $\mathrm{p}=0.0335)$. The maximum k-readings were 44.12 (SD \pm 3.97$)$ preoperatively, 46.23 (SD \pm 4.14 ) 1 month, 43.88 (SD \pm 4.25 ) 3 months, 45.06 (SD \pm 5.07$) 6$ months and 44.43 (SD \pm 4.06 ) 12 months postoperatively (statistically significant preop -postop1, $p=0.0281)$

Conclusion: Crosslinking in patients with iatrogenic keratectasia stabilized the UCVA and BCVA as well as the maximum k-readings in our cohort. It seems to be a safe and promising procedure to stabilize the refraction and the corneal topography, hence to stop the progression of visual loss, thereby avoiding or delaying disease progression and keratoplasty. 


\section{Introduction:}

Since the first description of laser in situ keratomileusis (LASIK)[1] several million patients have undergone this surgery. The intra and post operative complications were reduced with the improvement of the mechanical microkeratomes and the introduction of new femtosecond laser systems. However refractive surgery cuts and removes corneal tissue by creating a flap and removing tissue from the stromal bed. Therefore, in all excimer laser procedures, the corneal biomechanics are clearly weakened.[2, 3]

latrogenic keratectasia is a rare but major sight-threatening complication after LASIK[4] and was first described in 1998.[5] Since then, many reports of keratectasia have been published.[6-8] Keratectasia is characterized by a progressive corneal steepening which can occur centrally or inferiorly combined with severe refractive changes, loss of visual acuity (VA) and a stromal thinning of the cornea.[9] Risk factors for its development are thin corneas, a thin residual stromal bed, deep ablations, enhancement treatments and preoperative abnormalities like forme fruste keratoconus.[10, 11] Keratectasia also appears in eyes treated according to the current guidelines without any risk factors.[9]

It is important to diagnose this condition at an early stage in order to achieve or maintain good visual acuity and avoid severe procedures such as a keratoplasty. Various methods have been developed to address keratoconus which have also been used in post-LASIK keratectasia, such as rigid gas permeable contact lenses, intracorneal ring segments (e.g. INTACS), anterior lamellar and penetrating keratoplasty.[8, 12-15] However rigid contact lenses and intracorneal ring segments do not stop the progression of the disease. 
Corneal collagen crosslinking was first described in 1997[16] and soon utilised to treat keratoconus.[17] Crosslinking represents a photooxidative technique of collagen crosslinking using riboflavin as a photosensitizer for UV-A-light [18] and has the ability to increase the corneal biomechanical stability by inducing chemical covalent bonds, bridging amino groups of stromal collagen fibrils, thereby increasing their intra- and inter-fibrillar rigidity.[19] It has been used to arrest the progression of keratoconus since 2003.[17] The research and clinical studies have demonstrated that corneal crosslinking stabilizes the weakened cornea and refraction, halting the progression of keratoconus.[18, 20,21] Thus, it reduces the need for a keratoplasty in a majority of cases. Since keratectasia formation appears to be very similar to other ectatic conditions of the cornea, such as keratoconus or pellucid marginal degeneration, similar treatments have been used in order to manage post-LASIK ectasia.

The aim of this study was to evaluate the effect of corneal crosslinking in the treatment of post-LASIK keratectasia.

\section{Materials and Methods:}

In this prospective, non randomised clinical study 22 eyes of 15 patients (6 female, 9 male) with a history of LASIK and the development of iatrogenic keratectasia after LASIK were included. Ectasia was diagnosed according to Pallikaris et al. by the slitlamp appearance of corneal thinning in the area of ectasia, unstable topographical steepening (more than 1.0 diopter [D] , figure 1), decreased visual acuity, and/or unstable refraction.[22] The patients were referred to our clinic after the onset of symptoms of ectasia between 2 weeks and 10 years after the LASIK procedure 
(mean: 38.7 months, $S D \pm 35.1$ ). Symptoms included progressive loss of vision, blurry vision, and frequently changing refraction, with increasing myopia and astigmatism.

All patients underwent a full ophthalmic evaluation before corneal crosslinking treatment. This included a detailed history and a complete examination with objective (Topcon KR 8900, Topcon Deutschland GmbH, Willich Germany) and manifest refraction, uncorrected (UCVA) and best spectacle corrected visual acuity (BSCVA), a slit lamp examination, ultrasound pachymetry (Tomey SP3000, Tomey, Erlangen, Germany), corneal topography (Tomey TMS 4, Tomey, Erlangen, Germany), applanation tonometry (Goldmann Applanation Tonometer, Haag-Streit, Köniz, Switzerland) and a dilated fundus examination.

The inclusion criteria for treatment were progressive keratectasia after refractive surgery as well as a pachymetry greater then $400 \mu \mathrm{m}$. Exclusion criteria included corneal thickness less than $400 \mu \mathrm{m}$ and central corneal scars.

The corneal crosslinking was performed in the outpatient operating room under sterile conditions. The ocular surface was anaesthetized with topical proxymetacaine hydrochloride $0.5 \%$ eye drops (Proparacain $\AA$, Ursapharm, Saarbrücken, Germany, 2 drops at $30 \mathrm{sec}$ interval) followed by a mechanical corneal debridement of $8 \mathrm{~mm}$ in diameter.

To photosensitize and saturate the cornea, a topical $0.1 \%$ riboflavin isotonic solution (Medio-Haus Medizinprodukte $\mathrm{GmbH}$, Neudorf, Germany) was applied every five minutes for 30 minutes. After this period, a UV-A-irradiation $(370 \mathrm{~nm})$ with a surface irradiance of $3 \mathrm{~mW} / \mathrm{cm}^{2}$ was carried out with $10 \mathrm{~cm}$ distance for 30 minutes using a commercially available system (UV-X $\mathrm{X}^{\mathrm{TM}}$, Peschke, Nürnberg, Germany).[19] This surface irradiance was controlled and calibrated using the UV-A meter (LaserMate-Q, 
LASER 2000) before the patient was exposed. During the UV-A-exposure period, riboflavin was applied every 5 minutes to guarantee the required concentration and keep the cornea moistened. At the end of the surgery, the corneal surface was washed thoroughly with BSS, and a bandage contact lens (Pure Vision, Bausch \& Lomb, Berlin, Germany) soaked in levofloxacin $5 \mathrm{mg} / \mathrm{ml}$ (Oftaquix® sine, Santen, Germering, Germany) was applied until the epithelial closure was complete.

Until the removal of the bandage contact lens, the postoperative therapy consisted of topical preservative-free antibiotics (levofloxacin $5 \mathrm{mg} / \mathrm{ml}$ ) and lubrication (carbomer 2\%, Vidisic EDO® Gel, Dr. Mann GmbH, Berlin, Germany) six times a day. Diclofenac tablets (Diclofenac-ratiopharm® $50 \mathrm{mg}$, Ratiopharm, Ulm, Germany) and Pregabalin 75 mg (Lyrica $\AA$, Pfizer Pharma, Berlin, Germany) were distributed to the patient to be taken as needed.

Postoperatively, the patients were examined daily until complete reepithelialisation. Follow-up examinations, according to a standardized protocol, assessed patients' objective and manifest refraction, UCVA, BSCVA, slit-lamp biomicroscopy, ultrasound corneal pachymetry (Tomey SP-3000) and corneal topography (Tomey Topographic Modelling System, TMS-4) and were performed 1, 3, 6 and 12 months after corneal crosslinking. We also analysed following topographic indices: the surface asymmetry index (SAl) which detects alteration of corneal asymmetry by comparing areas of the cornea $180^{\circ}$ apart and acts as a disease progression marker; the surface regularity index (SRI) which can be used to predict the optical outcome one might expect from corneal topography values. The third index assessed was the keratoconus prediction index (KPI), a composite calculated index that gives a measure of certainty of detection of the diagnosis of keratoconus.[23] 
For statistical analysis GraphPad Instat software for Windows was used (GraphPad Software, Inc La Jolla, CA, USA). To test for normal distribution of the parameters we used the method of Kolmogorov and Smirnov and to evaluate the statistical significance we used a two-tailed paired $t$ test. $P$ values $>0.05$ were interpreted as statistical not significant, values between 0.01 to 0.05 were interpreted as statistical significant $\left({ }^{*}\right)$ and values between 0.001 to 0.01 as statistical very significant $\left(^{* *}\right)$.

\section{Results:}

The mean age of the patients at the time of onset of keratectasia was 38.4 years (SD \pm 8.13 , range 27-51). The surgical procedure was uneventful in all cases. Postoperatively, a trace haze was present in 10 eyes and disappeared during the first three months.

The mean UCVA and BSCVA are shown in Figure 2. The UCVA changed from 0.53 $(S D \pm 0.38) \log M A R$ preoperatively to 0.67 (SD \pm 0.43 ) logMAR 1 month after corneal crosslinking. After 3 months, UCVA was 0.54 (SD \pm 0.35 ) logMAR. The 6-month postoperative evaluation showed an UCVA of $0.53(\mathrm{SD} \pm 0.35) \log M A R$, and after the first year, we had a mean UCVA of $0.40(S D \pm 0.27) \log M A R$. The changes were not statistically significant.

The preoperative BSCVA was 0.19 (SD $\pm 0,21$ ) logMAR and changed to 0.25 (SD $\pm 0.17) \log M A R$ after the first postoperative month. After 3 months, BSCVA was 0.20 $(S D \pm 0.20) \log M A R$ and was $0.18(S D \pm 0.21) \log M A R 6$ months after corneal crosslinking. The 12-month results showed a mean BSCVA of 0.15 (SD \pm 0.14 ) logMAR. The change from 1 month postoperatively to 6 months postoperatively was statistically significant $\left(p=0.0335^{*}\right)$. All other changes were not statistically significant. 
The refractive changes are shown in Figure 3. The spherical equivalent changed from -2.39 D (SD \pm 2.03 ) preoperatively to $-3.31 \mathrm{D}(\mathrm{SD} \pm 3.33) 1$ month, $-2.67 \mathrm{D}$ (SD $\pm 2.38) 3$ months, $-2.56 \mathrm{D}(\mathrm{SD} \pm 2.65) 6$ months and $-2.07 \mathrm{D}$ (SD \pm 2.18$) 12$ months after corneal crosslinking. The changes from preoperatively to 6 months postoperatively $\left(p=0.0404^{*}\right)$ and from 1 month postoperatively to 6 months postoperatively $\left(\mathrm{p}=0.0269{ }^{*}\right)$ were statistically significant. All other changes were not statistically significant.

The manifest cylinder (Figure 3) changed from -2.59 D (SD \pm 1.86$)$ preoperatively to $2.17 \mathrm{D}(\mathrm{SD} \pm 1.38) 1$ month, $-1.88 \mathrm{D}(\mathrm{SD} \pm 1.57) 3$ months, $-2.15 \mathrm{D}(\mathrm{SD} \pm 1.59) 6$ months and $-2.10 \mathrm{D}(\mathrm{SD} \pm 1.58) 12$ months after corneal crosslinking. The changes were not statistically significant.

The k-values are shown in Figure 4. The maximum and minimum k-readings were, respectively, 44.12 $\mathrm{D}(\mathrm{SD} \pm 3.97)$ and $41.78 \mathrm{D}(\mathrm{SD} \pm 2.69)$ preoperatively, 46.23 $\mathrm{D}$ (SD \pm 4.14$)$ and 43.25 D (SD \pm 2.66$) 1$ month, 43.88 $\mathrm{D}(\mathrm{SD} \pm 4.25)$ and 41.20 D (SD $\pm 2.88) 3$ months, 45.06 D (SD \pm 5.07$)$ and $42.20 \mathrm{D}(\mathrm{SD} \pm 3.22) 6$ months and $44.43 \mathrm{D}$ $(\mathrm{SD} \pm 4.06)$ and $42.04 \mathrm{D}(\mathrm{SD} \pm 2.67) 12$ months after corneal crosslinking. The change from preoperatively to 1 month postoperatively was statistically significant $(p=0.0281$ *) in the maximum k-readings. All other changes in the maximum k-readings as well as all changes in the minimum k-readings were not statistically significant.

The topographic astigmatic values (Figure 3) were -2.34 D (SD \pm 2.09 ) preoperatively, $-2.98 \mathrm{D}(\mathrm{SD} \pm 1.97) 1$ month, $-2.69 \mathrm{D}(\mathrm{SD} \pm 1.79) 3$ months, $-2.86 \mathrm{D}(\mathrm{SD} \pm 2.22) 6$ 
months and -2.39 $D(S D \pm 1.80) 12$ months after the operation. The changes were not statistically significant.

The mean SRI preoperatively was $1.13(\mathrm{SD} \pm 0.63)$. In the first postoperative month the mean SRI changed to 1.42 (SD \pm 0.57 ), three months after crosslinking it was 1.01 (SD \pm 0.48$)$, six months after surgery 1.01 (SD \pm 0.61$)$ and 12 months after crosslinking 0.73 (SD \pm 0.53 ). The changes from preoperatively to 12 months $\left(p=0.0077^{* *}\right)$ and from 1 month to 12 months postoperatively $\left(p=0.0017^{* *}\right)$ were statistically very significant. All other changes were not statistically significant.

Preoperatively the mean SAI was 1.84 (SD \pm 134$), 1$ month after crosslinking it increased to 2.62 (SD \pm 1.45 ), 3 months postoperatively it changed to 1.83 (SD $\pm 1.43)$. 6 months postoperatively the SAI was 1.79 (SD \pm 1.41$)$ and 12 months after crosslinking 1.49 (SD \pm 1.11 ). The changes were not statistically significant.

Preoperatively the mean KPI was 0.32 (SD \pm 0.12$), 1$ month after crosslinking it increased to 0.38 ( $S D \pm 0.12$ ), 3 months it decreased to 0.30 (SD \pm 0.11 ). 6 months after crosslinking the KPI was 0.31 (SD \pm 0.12 ) and 12 months postoperatively it was 0.29 (SD \pm 0.11 ). The change from the first postoperative month to the third postoperative month was statistically significant $\left(p=0.0291^{*}\right)$. All other changes were not significant.

\section{Discussion:}

latrogenic keratectasia still lacks an efficacious and predictable treatment option. 
Corneal crosslinking is known to work mainly in the anterior two thirds of the cornea. $[9,24]$ This represents a challenge using corneal crosslinking in post-LASIK ectasia, for the flap does not contribute to the mechanical stability of the cornea. Hence, we would expect it to be less effective in this situation compared to the treatment of keratoconus or PMD.

Up to now only two papers have been published regarding corneal crosslinking exclusively in post-LASIK ectasia. Kohlhaas et al. reported first about a successful treatment of a post-LASIK ectasia using corneal crosslinking back in 2005 in one patient with ectasia on both eyes.[9] In 2007 Hafezi et al.[11] published first results of corneal crosslinking in post-LASIK ectasia showing an arrest and even a partial reversal in the keratectasia.

Our results showed a worsening of both the uncorrected as well as the best spectacle corrected visual acuity in the first postoperative month (a non significant loss of 1.5 lines in UCVA and of 0.5 lines in BSCVA). This change in visual acuity could be related to an increase in myopia and a consequent statistical non significant increase in the spherical equivalent. This myopic shift would explain the decrease in visual acuity and could be, in our opinion, due to a modification in the corneal shape resulting from the compaction of the stromal collagen following the crosslink process. The increasing myopia goes along with increased topographic values (k-max, k-min, keratometric cylinder, SRI, SAI and $\mathrm{KPI}$ ) reflecting a steepening of the cornea and an increase of an irregular astigmatism. A trace haze was present in 10 eyes which disappeared within the first three postoperative months and could also explain a slight myopic shift. After this period, the myopia and the spherical equivalent continuously diminished. The spherical equivalent improved significantly from the preoperative value as well as the first postoperative to the sixth postoperative month. 
There were some non significant fluctuations in the manifest cylinder along with the corneal topography.

UCVA as well as BSCVA recovered after the third postoperative month and remained stable throughout the follow-up period of 12 months with a statistically significant increase of BSCVA. Parallel to these changes the corneal indices also give us hints about the corneal shape and ectasia existence/evolution. In our series preoperative SRI and SAl were outside of the normal range published by Burns et al.[23], revealing a corneal asymmetry compatible with post LASIK ectasia.[8] KPI also showed preoperative values consistent with corneal ectasia (according to TMS-4 $>0.24$ ectasia suspect).

All three analysed indices regressed after the first postoperative month during the follow-up period. According to the index definitions of Burns et al.[23] the statistical significant reduction of KPI and statistically significant regression of the SRI support a regression of the corneal ectasia with a flattening of the cornea.

In our study, corneal crosslinking seems to be an effective option in the treatment of post-LASIK ectasia.

The stabilisation of VA and of the corneal curvature, and in some cases even an improvement in VA and reversal of the corneal ectasia in our study correlates well with the results published by Kohlhaas and Hafezi.

There are, however, a few disadvantages to corneal crosslinking: thus far, researchers have not been able to monitor the long-term experience of patients, nor can they accurately predict the long-term effects of a single procedure.

Nevertheless, the results from the first six years of the crosslinking treatment of keratoconus are very promising. There are few reports of patients requiring a second crosslinking in the same eye.[18] Complications are very rare and include sterile infiltrates, stromal scars and haze. Corneal infection is a reported complication which 
is unlikely directly related to the crosslinking itself, since crosslinking acts as a bactericide and fungicide .[24]

latrogenic keratectasia remains a rather obscure subject. The underlying problem has not been yet fully understood which makes keratectasia difficult to control. As we see in our cohort, ectasia can present quickly after a refractive procedure, but it can also appear years after surgery. In our opinion, the most important step in the management of iatrogenic keratectasia is to monitor refractive patients regularly, even years after the laser procedure, in order to diagnose and try to treat such a complication at an early stage.

Corneal crosslinking is a promising procedure in the treatment of post-LASIK keratectasia, but we need to await the long-term results of a greater number of patients in randomized controlled trials in order to confirm its efficacy, safety and durability.

\section{Licence for Publication}

The following statement must be included in your manuscript:

"I ,Josefina Salgado, the Corresponding Author of this article "Corneal Collagen Crosslinking in post-LASIK keratectasia" has the right to grant on behalf of all authors and does grant on behalf of all authors, a licence to the BMJ Publishing Group Ltd and its licensees, to permit this Contribution (if accepted) to be published in British Journal of Ophthalmology (BJO) and any other BMJ Group products and to exploit all subsidiary rights, as set out in our licence set out at: (http://bjo.bmj.com/site/about/licence.pdf) [IF YOU ARE A NATIONAL INSTITUTE OF HEALTH ("NIH") EMPLOYEE, CONTRACTOR OR TRAINEE ADD: I am a National Institute of Health ("NIH") employee, contractor or trainee , and the following cover sheet will be accepted by the BMJ Group and NIH and incorporated into the above Licence (http://bjo.bmj.com/site/about/licence.pdf).]

Please tick one or more boxes as appropriate:

$\square \mathrm{I}$ am the sole author of the Contribution.

x I am one author signing on behalf of all co-owners of the Contribution.

$\square$ The Contribution has been made in the course of my employment and I am signing as authorised by my employer. 
$\square$ I am a US Federal Government employee acting in the course of my employment.

$\square$ I am not a US Federal Government employee, but some or all of my co-authors are.

$\square$ I am an employee of the UK Government acting in the course of my employment

I am not an employee of the UK Government acting in the course of my employment but some/all of my co-authors are.

Kind regards

Josefina Salgado , MD

Competing Interest: none

\section{References:}

1. Pallikaris IG, Papatzanaki ME, Siganos DS et al. A corneal flap technique for laser in situ keratomileusis. Human studies. Arch Ophthalmol 1991Dec,109(12):1699702.

2. Dupps WJ, Jr., Wilson SE. Biomechanics and wound healing in the cornea. Exp Eye Res 20060ct,83(4):709-20.

3. Krueger RR, Dupps WJ, Jr. Biomechanical effects of femtosecond and microkeratome-based flap creation: prospective contralateral examination of two patients. J Refract Surg 2007Oct,23(8):800-7.

4. Comaish IF, Lawless MA. Progressive post-LASIK keratectasia: biomechanical instability or chronic disease process? J Cataract Refract Surg 2002Dec,28(12):2206-13. 
5. Seiler T, Koufala K, Richter G. latrogenic keratectasia after laser in situ keratomileusis. J Refract Surg 1998May-Jun,14(3):312-7.

6. Ou RJ, Shaw EL, Glasgow BJ. Keratectasia after laser in situ keratomileusis (LASIK): evaluation of the calculated residual stromal bed thickness. Am $\mathrm{J}$ Ophthalmol 2002Nov, 134(5):771-3.

7. Kymionis GD, Tsiklis N, Karp CL et al. Unilateral corneal ectasia after laser in situ keratomileusis in a patient with uncomplicated photorefractive keratectomy in the fellow eye. J Cataract Refract Surg 2007May,33(5):859-61.

8. Argento $\mathrm{C}$, Cosentino MJ, Tytiun $\mathrm{A}$ et al. Corneal ectasia after laser in situ keratomileusis. J Cataract Refract Surg 2001Sep,27(9):1440-8.

9. Kohlhaas M, Spoerl E, Speck A et al. [A new treatment of keratectasia after LASIK by using collagen with riboflavin/UVA light cross-linking]. Klin Monbl Augenheilkd 2005May,222(5):430-6.

10. Binder PS. Ectasia after laser in situ keratomileusis. J Cataract Refract Surg 2003Dec,29(12):2419-29.

11. Hafezi F, Kanellopoulos J, Wiltfang R et al. Corneal collagen crosslinking with riboflavin and ultraviolet $A$ to treat induced keratectasia after laser in situ keratomileusis. J Cataract Refract Surg 2007Dec,33(12):2035-40.

12. Tan DT, Por YM. Current treatment options for corneal ectasia. Curr Opin Ophthalmol 2007Jul,18(4):284-9.

13. Rabinowitz YS. Intacs for keratoconus. Curr Opin Ophthalmol 2007Jul,18(4):279-83.

14. Bilgihan $\mathrm{K}$, Ozdek SC, Sari A et al. Excimer laser-assisted anterior lamellar keratoplasty for keratoconus, corneal problems after laser in situ keratomileusis, and corneal stromal opacities. J Cataract Refract Surg 2006Aug,32(8):1264-9. 
15. Rodriguez LA, Guillen PB, Benavides MA et al. Penetrating keratoplasty versus intrastromal corneal ring segments to correct bilateral corneal ectasia: preliminary study. J Cataract Refract Surg 2007Mar,33(3):488-96.

16. Sporl E, Huhle M, Kasper M et al. [Increased rigidity of the cornea caused by intrastromal cross-linking]. Ophthalmologe 1997Dec,94(12):902-6.

17. Wollensak G, Spoerl E, Seiler T. Riboflavin/ultraviolet-a-induced collagen crosslinking for the treatment of keratoconus. Am J Ophthalmol 2003May,135(5):6207.

18. Raiskup-Wolf $F$, Hoyer A, Spoerl E et al. Collagen crosslinking with riboflavin and ultraviolet-A light in keratoconus: long-term results. J Cataract Refract Surg 2008May,34(5):796-801.

19. Wollensak G. Crosslinking treatment of progressive keratoconus: new hope. Curr Opin Ophthalmol 2006Aug, 17(4):356-60.

20. Kohlhaas M. [Collagen crosslinking with riboflavin and UVA-light in keratoconus]. Ophthalmologe 2008Aug,105(8):785-93; quiz 94.

21. Wittig-Silva $\mathrm{C}$, Whiting $\mathrm{M}$, Lamoureux $\mathrm{E}$ et al. A randomized controlled trial of corneal collagen cross-linking in progressive keratoconus: preliminary results. $\mathrm{J}$ Refract Surg 2008Sep,24(7):S720-5.

22. Pallikaris IG, Kymionis GD, Astyrakakis NI. Corneal ectasia induced by laser in situ keratomileusis. J Cataract Refract Surg 2001Nov,27(11):1796-802.

23. Burns DM, Johnston FM, Frazer DG et al. Keratoconus: an analysis of corneal asymmetry. Br J Ophthalmol 2004Oct,88(10):1252-5.

24. Koller $\mathrm{T}$, Mrochen $\mathrm{M}$, Seiler $\mathrm{T}$. Complication and failure rates after corneal crosslinking. J Cataract Refract Surg 2009Aug,35(8):1358-62.

\section{Acknowledgements:}




\section{Legends for display items (Figures and Tables):}

Figure 1: $\quad$ Example of untreated corneal ectasia evolution over 7 months

Figure 2: Variation of UCVA and BSCVA during the whole follow up

Figure 3: Changes of sphere, cylinder and spherical equivalent

Figure 4: Changes in $\mathrm{k}$ readings during the first year ( $\mathrm{k}-\mathrm{max}$, and $\mathrm{k}-\mathrm{min}$ ) 


\section{Power Difference Map} A - B

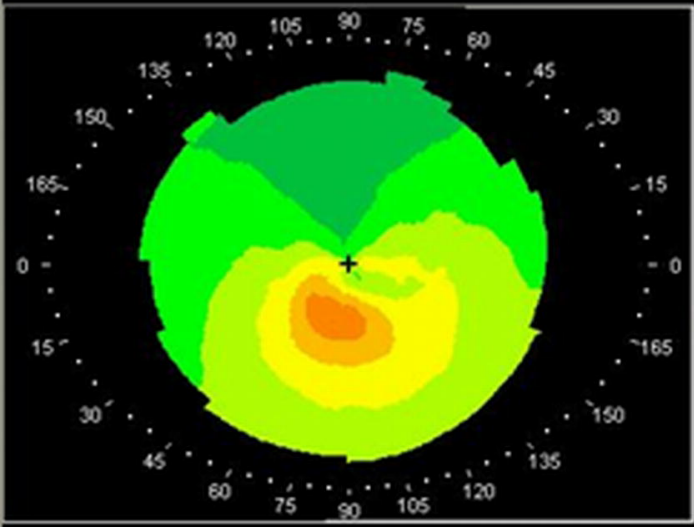

Power Difference (2.000 D)

\section{B}

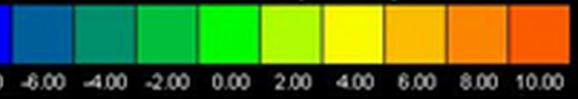

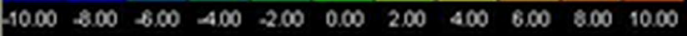

Cylinder change: $0.43 \mathrm{D}$ (Induced: $2.43 \mathrm{D} Q 147$ ) Mean power difference: $2.66 * 2.67 \mathrm{D}(\mathrm{N}=2821)$

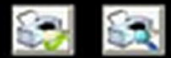

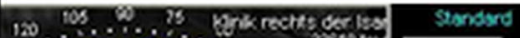

A
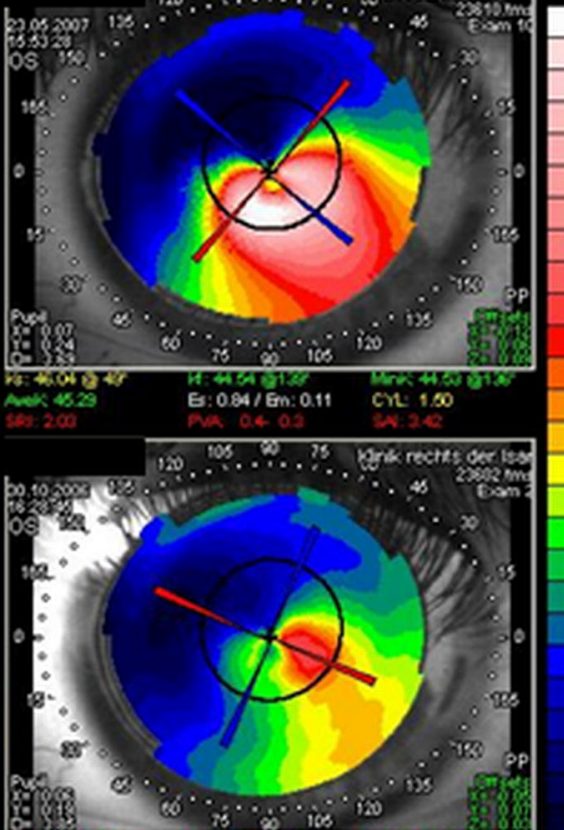

60

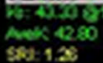

$\sec 120$

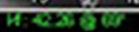

(a)

E: $0.44 / \mathrm{Em}: 0.4$

crit 100

PNA 0.0.0.5

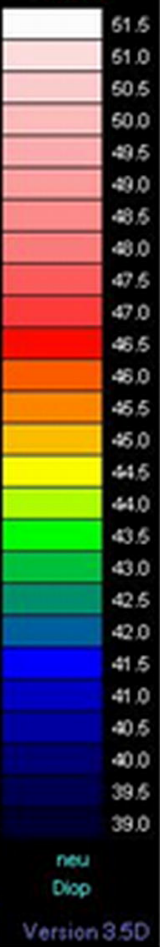




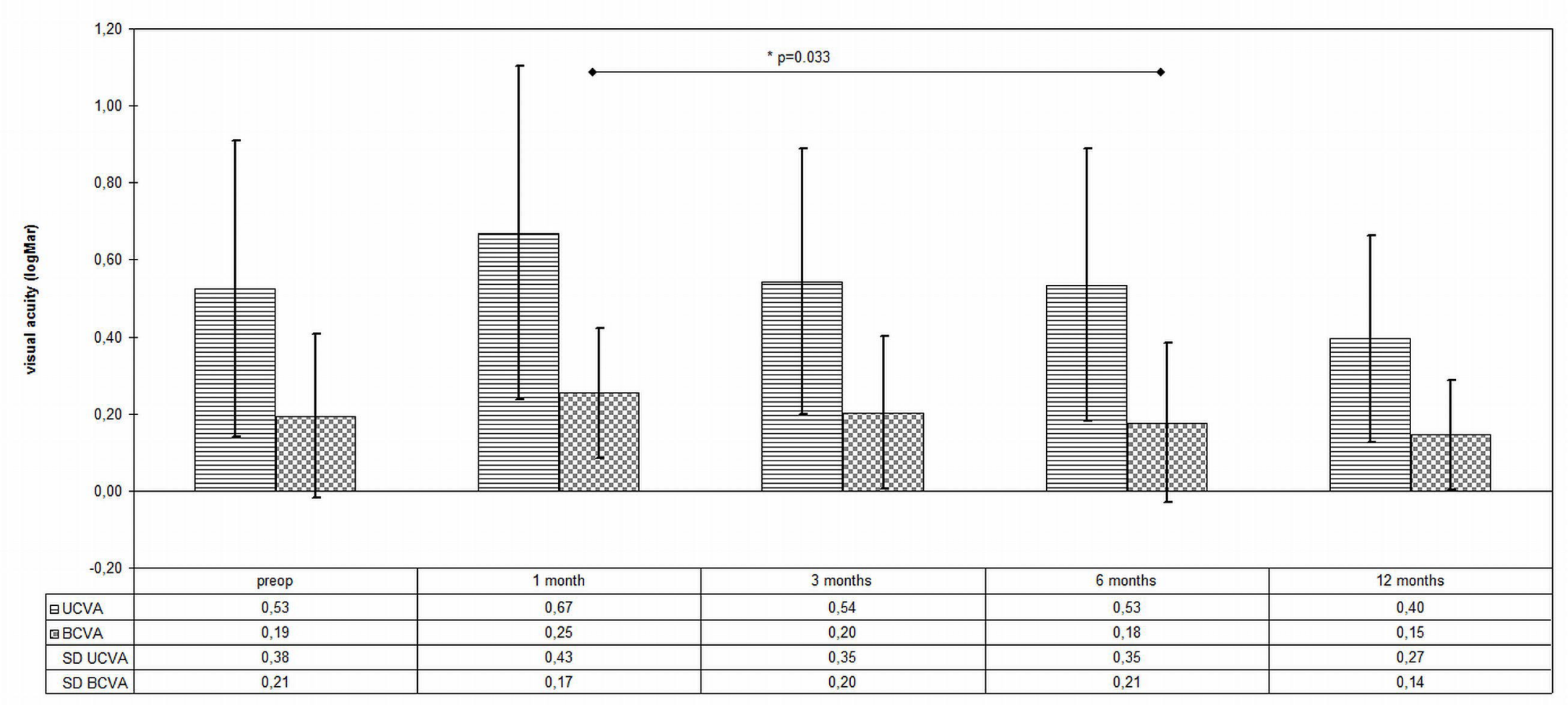




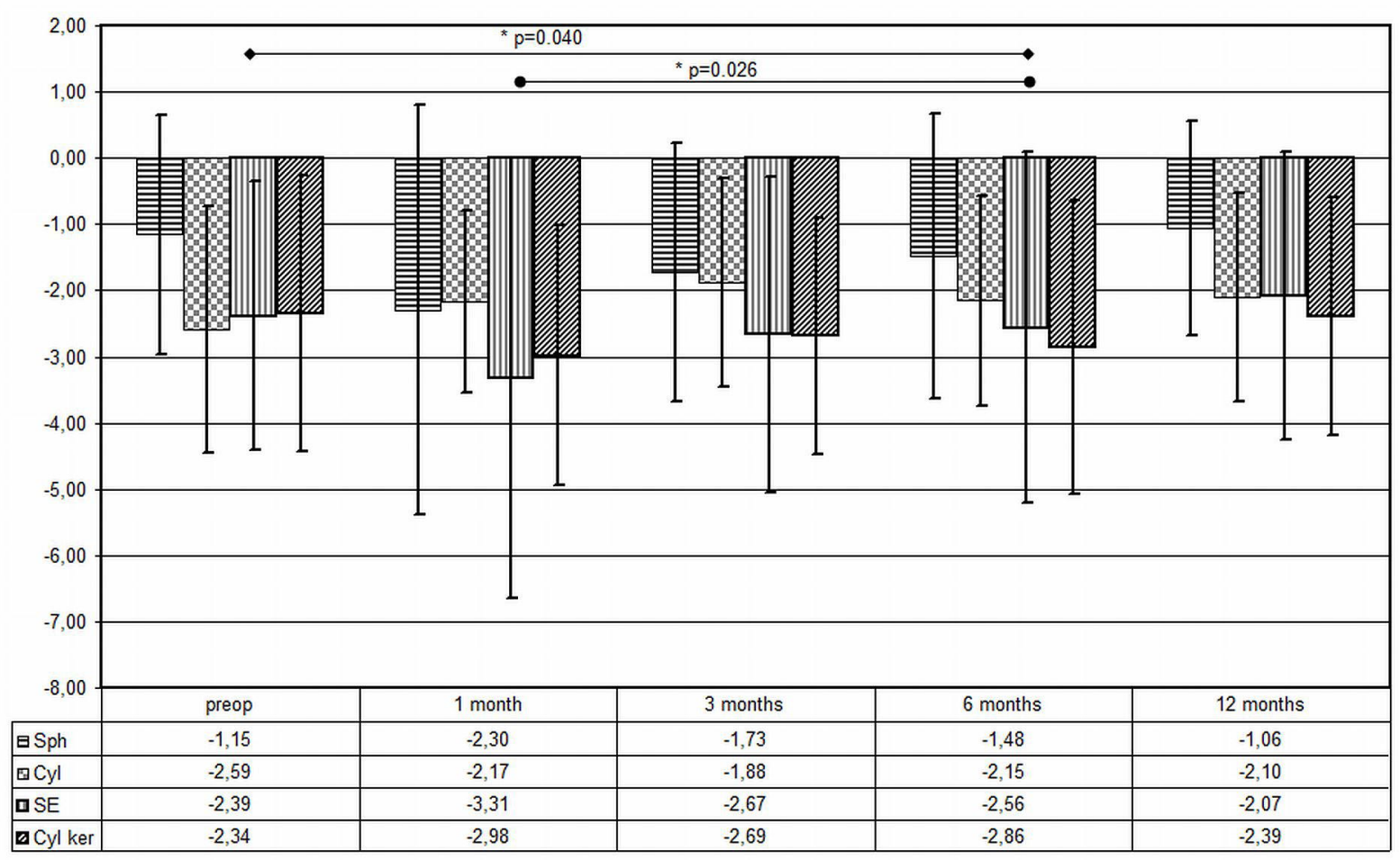




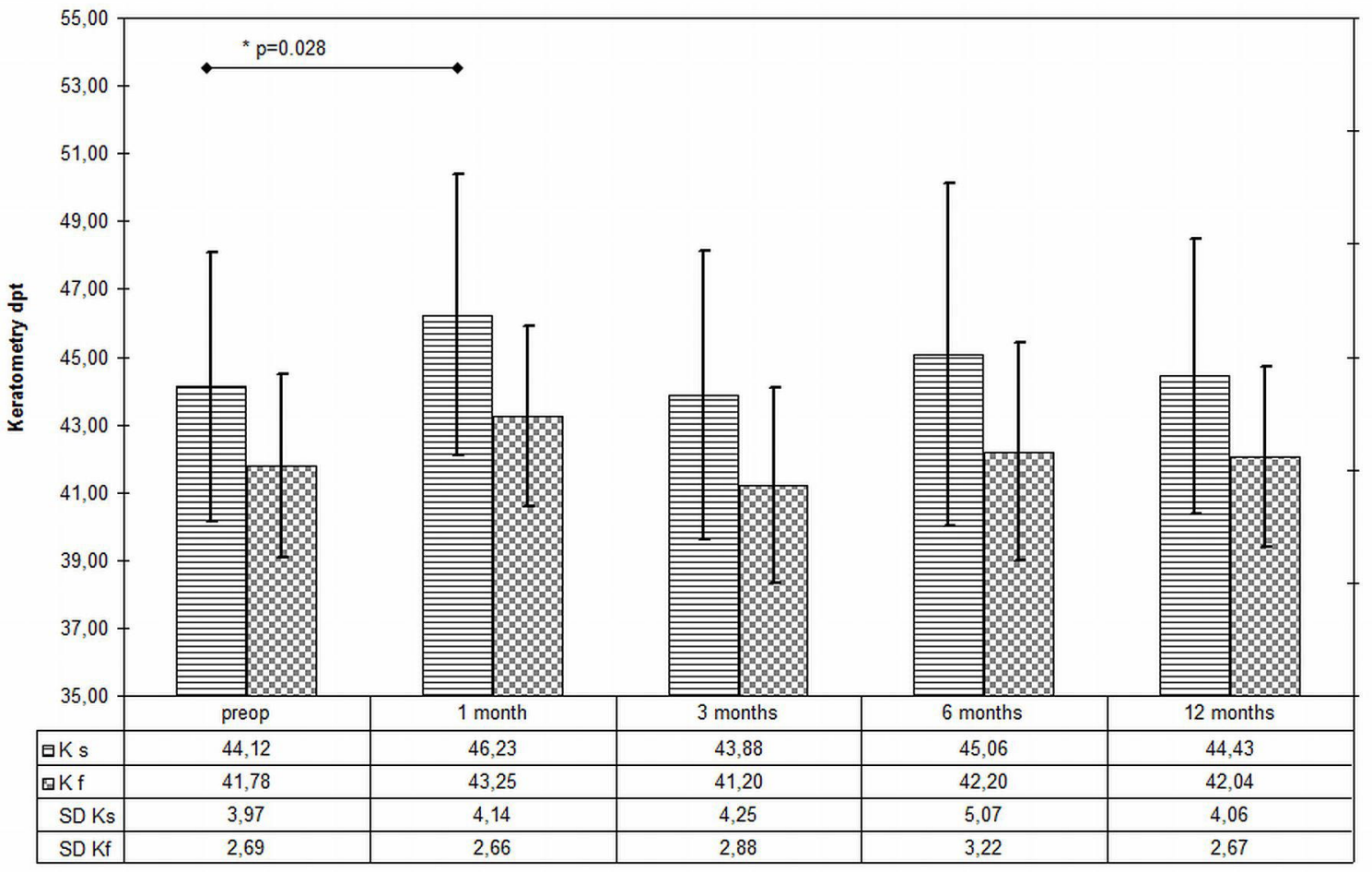

